\title{
Inkjet printing of paraffin on paper allows low-cost point-of- care diagnostics for pathogenic fungi
}

\author{
Anusha Prabhu • M. S. Giri Nandagopal - Prakash Peralam Yegneswaran • \\ Hardik Ramesh Singhal • Naresh Kumar Mani 10
}

Received: 9 April 2020/ Accepted: 24 June 2020/Published online: 2 July 2020

(C) The Author(s) 2020

\begin{abstract}
We present a high resolution, ultra-frugal printing of paper microfluidic devices using in-house paraffin formulation on a simple filter paper. The patterns printed using an office inkjet printer formed a selective hydrophobic barrier of $4 \pm 1 \mu \mathrm{m}$ thickness with a hydrophilic channel width of $275 \mu \mathrm{m}$. These printed patterns effectively confine common aqueous solutions and solvents, which was verified by solvent compatibility studies. SEM analysis reveals that the solvent confinement is due to pore blockage in the
\end{abstract}

Electronic supplementary material The online version of this article (https://doi.org/10.1007/s10570-020-03314-3) contains supplementary material, which is available to authorized users.

\footnotetext{
A. Prabhu · N. K. Mani ( $\square)$

Department of Biotechnology, Manipal Institute of Technology, Manipal Academy of Higher Education, Manipal, Karnataka 576104, India

e-mail: naresh.mani@manipal.edu;

maninaresh@gmail.com

M. S. Giri Nandagopal

Department of Mechanical Engineering, Indian Institute

of Technology, Kharagpur, Kharagpur, 721302, India

P. Peralam Yegneswaran

Department of Microbiology, Kasturba Medical College

Manipal, Manipal Academy of Higher Education,

Manipal, Karnataka 576104, India
}

filter paper. The fabricated paper-based device was validated for qualitative assessment of Candida albicans (pathogenic fungi) by using a combination of L-proline $\beta$-naphthylamide as the substrate and cinnamaldehyde as an indicator. Our studies reveal that the pathogenic fungi can be detected within $10 \mathrm{~min}$ with the limit of detection (LOD) of $0.86 \times 10^{6} \mathrm{cfu} /$ $\mathrm{mL}$. Owing to its simplicity, this facile method shows high potential and can be scaled up for developing robust paper-based devices for biomarker detection in resource-limited settings.

P. Peralam Yegneswaran · N. K. Mani

Manipal-McGill Centre for Infectious Diseases, Prasanna School of Public Health, Manipal Academy of Higher Education, Manipal, Karnataka 576104, India

H. R. Singhal

Department of Chemical Engineering, Manipal Institute of Technology, Manipal Academy of Higher Education, Manipal, Karnataka 576104, India 


\section{Graphic abstract}

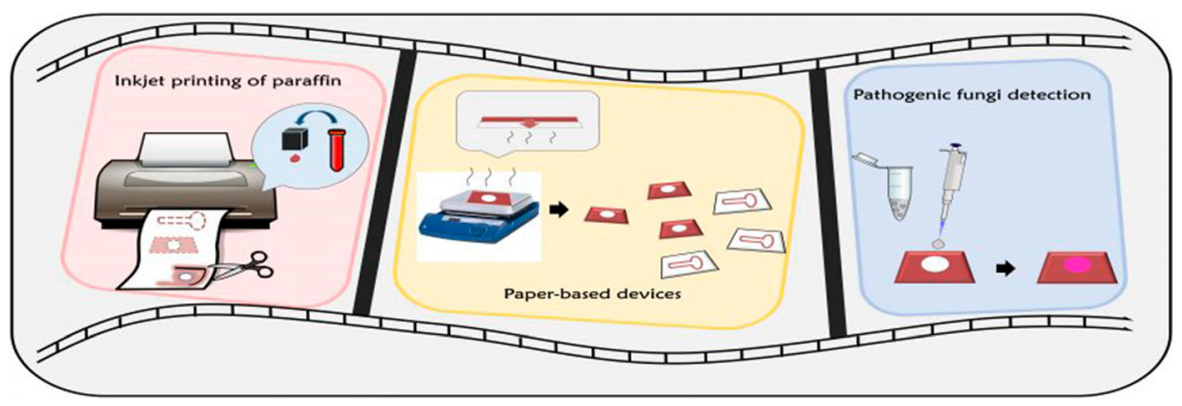

Keywords Inkjet printing - Paraffin formulation Candida albicans $\cdot$ Point-of-care

\section{Introduction}

Most often, the presence of microbial pathogens (including bacteria, fungi, viruses and parasites) inside and around humans has been shown to have detrimental effects on their health, which ranges from mild infections all the way up to lethal diseases (Savary et al. 2019; Chow et al. 2010). As a result, pathogen detection is more imperative than ever and is readily employed in wide-spread areas like food testing (Priyanka et al. 2016), environmental monitoring (Rajapaksha et al. 2019) and clinical diagnosis (Lazcka et al. 2007). Recent times have seen a steady increase in antimicrobial resistance and delayed disease detection which has become a bludgeoning problem among patient care and hospital settings (Prestinaci et al. 2015). Therefore, the development of efficient diagnostic technique is now of paramount importance. Conventional and frugal ways of detecting causative pathogens mainly rely on culture-based methods, where the samples are isolated and grown in a suitable media. Later, the cultured samples are subjected to microscopic examination, biochemical testing and chromogenic media for detection (Wormser and Ryan 2003; Law et al. 2014; Prestinaci et al. 2015; Váradi et al. 2017). Though the said methods are cheap, robust and well-implemented for clinical samples, they are less sensitive and requires frequent media preparation, expert intervention and longer assay time. This, eventually results in delayed detection as well as targeted therapy (Wang and Salazar 2016; Goluch 2017).

As a result, the last decade has seen rapid progress in the field of pathogen detection due to advancements in optical biosensors (Lazcka et al. 2007) and microfluidics (Kou et al. 2016). Microfluidics technology in particular has made significant contributions in chemical assays (Yeo et al. 2011), single-molecule manipulation (Mani et al. 2013), biomedical sensing (Whitesides 2006) and more importantly, point-ofcare diagnostics (Nasseri et al. 2018). In the interest of developing frugal point-of-care diagnostic devices 'Paper' has been shown to hold great promise as a viable material as it is affordable, abundant, biodegradable and highly porous. Additionally, surface of paper possesses hydrophilic groups, which facilitate sample movement via capillary flow without necessitating external pumps (Songok et al. 2014). Owing to its myriads of benefits, paper is considered as the better candidate for diagnostic device development when compared to its counterparts, namely polymers and glass (Liu et al. 2019; Tang et al. 2020). As a result of its versatility, paper platforms have also been combined with electrochemical, colorimetric and fluorescence detection systems for sensing various analytes, biomarkers and other applications (Ahmed et al. 2016; Chatterjee et al. 2018; Lee et al. 2018; Rosati et al. 2019; Xiao et al. 2019; Mani et al. 2020; Lin et al. 2020; e Silva et al. 2020).

A significant step in transforming paper into a paper-based device mainly relies on the patterning of hydrophobic barriers. This can be achieved by using conventional and low-throughput techniques like photolithography (OuYang et al. 2014; He et al. 2013), vapour phase deposition (Haller et al. 2011; 
Kwong and Gupta 2012), screen printing (Dungchai et al. 2011; Sameenoi et al. 2014), flexography printing (Olkkonen et al. 2010), plasma treatment ( $\mathrm{Li}$ et al. 2008), wax dipping (Songjaroen et al. 2011) and correction pens (Mani et al. 2019). Alternatively, highthroughput wax printing (Lu et al. 2009; Carrilho et al. 2009; Nilghaz et al. 2019) and inkjet printing (Abe et al. 2008; Li et al. 2010; Elsharkawy et al. 2014; Yamada et al. 2015; Su et al. 2016; Matsuda et al. 2017; Punpattanakul et al. 2018) are also used to make paper-based microfluidic devices for chemical sensing and diagnostic purposes ( $\mathrm{Li}$ et al. 2012; Yang et al. 2017).

The main drawbacks of commercial wax printers are their high cost $(>150 \$)$, poor compatibility to organic solvents (Wang et al. 2014) and unavailability in developing countries (Lin et al. 2020), primarily due to constraints in affordability and service rendering. In addition to that, the exact ink composition of commercially available Xerox Phaser and Colorqube (solid wax printer) is a trade secret (Potter et al. 2019), therefore hindering their reproducibility even more. Hence, there is a growing interest towards the development of alternative facile fabrication methods. In this work, we have developed a high-throughput, robust, ultra-frugal inkjet printing set-up $(<25 \$)$ with an in-house formulation (based on "paraffin wax", heptane, colorant) which we have used to achieve selective hydrophobization on a paper surface (Fig. 1). This hydrophobic formulation is inert, opaque and compatible with major aqueous and organic solvents. Additionally, we have achieved a hydrophilic channel resolution of $275 \mu \mathrm{m}$. As a novel application, we have leveraged the printed paraffin-based paper devices for the rapid $(<10 \mathrm{~min})$ and qualitative detection of pathogenic fungi Candida albicans, which is prevalent among immunocompromised patients and neonates.

\section{Materials and methods}

\section{Materials}

Whatman $^{(\mathrm{R})}$ filter paper (Grade 1) of $180 \mu \mathrm{m}$ thickness and $11 \mu \mathrm{m}$ pore size was purchased from GE Life Sciences. Paraffin was purchased from Merck, India. n-Heptane was obtained from SRL, India and colorants (red and green) were procured from local candle manufacturer. L-proline $\beta$-naphthylamide (PRO) was procured from Sigma Aldrich, India and p-dimethylaminocinnamaldehyde (DCA) was obtained from Loba Chemie, India. Other chemicals (analytical grade) were purchased from Merck, SRL, Loba Chemie and Himedia. Candida albicans (ATCC 24433) strain was obtained from the culture collection at Mycology Laboratory, Department of Microbiology, Kasturba Medical College, Manipal.

Preparation of paraffin formulation

The paraffin formulation was prepared using a mixture of Paraffin, n-Heptane and colorant.

The paraffin was initially prepared in $n$-Heptane solvent at $6.5 \%(\mathrm{w} / \mathrm{v})$ solution. $20 \mu \mathrm{L}$ of the colorant was further added to the prepared solution and vortexed gently. The surface tension of prepared paraffin formulation was found to be $20.18 \mathrm{mN} / \mathrm{m}$.

Inkjet printing of paper-based devices

A HP Deskjet printer (1112) was used to print the hydrophobic formulation by replacing the original ink in the cartridge with the in-house formulation. The ink formulation was filled in the printer cartridge using a syringe. The cartridge was cleaned rigorously using $\mathrm{n}$-Heptane and Isopropyl alcohol before filling the ink formulation and loading it into the printer. The pattern of the hydrophobic barrier for the paper devices were designed using CorelDraw X6 software and printed 15 times on single side of Whatman ${ }^{(\mathrm{R})}$ filter paper (Grade 1). The cartridge was frequently refilled using the syringe after depletion. The printed sheet of paper was placed in a hot air oven set at $100{ }^{\circ} \mathrm{C}$ for $15 \mathrm{~min}$ to allow the paraffin to penetrate into the paper pores. The minimum hydrophobic barrier width achieved was $3 \mathrm{~mm}$. The thickness of the uncoated and coated filter paper was measured using a Mitutoyo Digital Micrometer (293-831). As per the manufacturer's guidelines, the volume of droplet deposited by HP Deskjet 1112 printer cartridge is 22 picolitre. (https:// store.hp.com/in-en/default/hp-803-2-pack-economyblack-ink-cartridges-3yp94aa.html).

\section{Surface characterization}

Surface analysis of coated and uncoated paper was performed using a JEOL Scanning Electron Microscope. The water penetration rate (lateral) for plain 


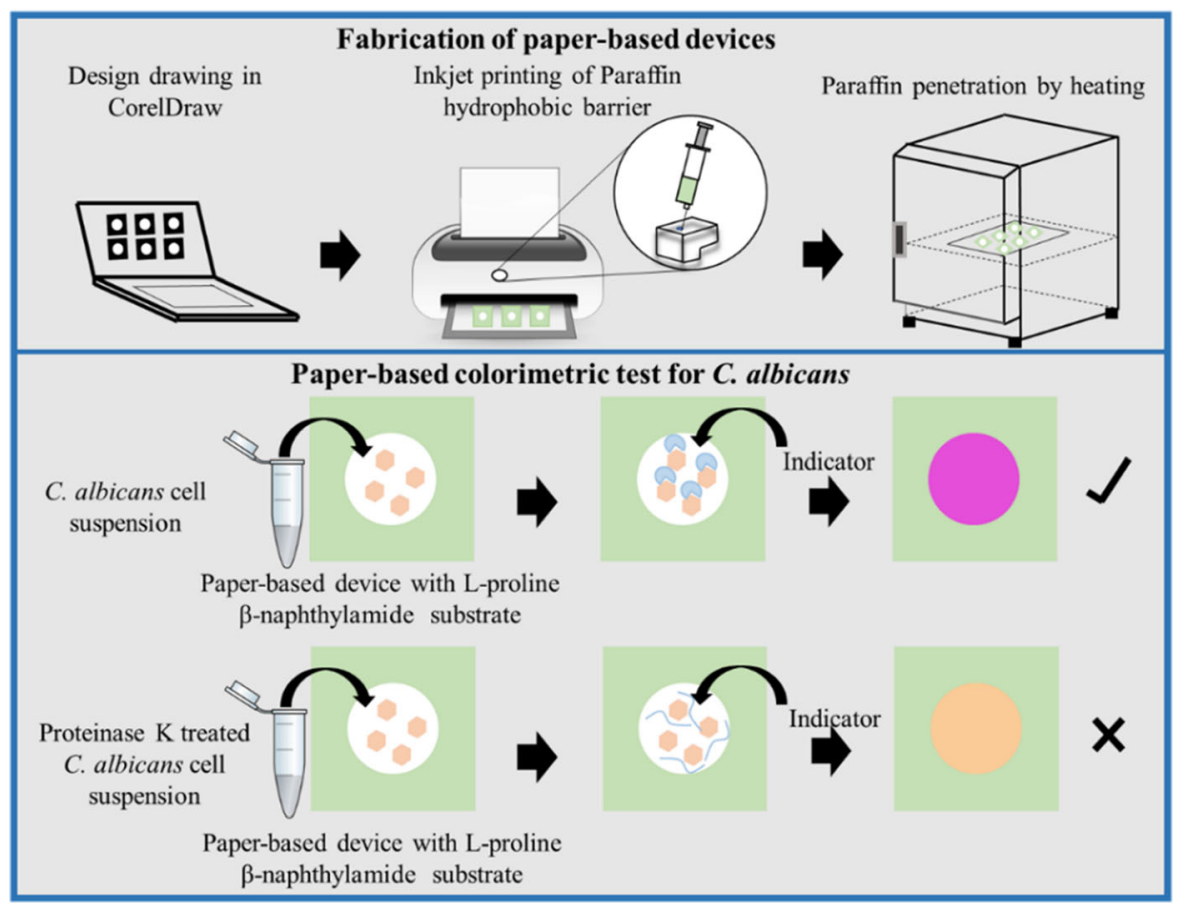

Fig. 1 Schematic illustration of inkjet printing of paraffin on paper (Top). Paper-based colorimetric test for the detection of Candida albicans (Bottom)

paper and the hydrophobic barrier device was determined using a measuring scale and a timer.

\section{Paper-based assay for Candida albicans}

Initially, an assay for Candida albicans was conducted in a vial by taking L-proline $\beta$-naphthylamide (PRO) as a substrate and Cinnamaldehyde as a colorimetric indicator. Here, $50 \mu \mathrm{L}$ of the PRO substrate solution $(2 \mathrm{mg} / \mathrm{mL})$ was taken in a vial followed by the addition of $200 \mu \mathrm{L}$ sample of Candida albicans (ATCC 24433) in water. This suspension was incubated at $37{ }^{\circ} \mathrm{C}$ for $15 \mathrm{~min}$. Later, $80 \mu \mathrm{L}$ of the colorimetric indicator was added and was checked for pink colour formation. This study was extended to the inkjet-printed paper-based devices. Here, $50 \mu \mathrm{L}$ of the PRO substrate solution $(2 \mathrm{mg} / \mathrm{mL})$ was dropcasted into the circular inkjet-printed paper device and allowed to dry for about $15 \mathrm{~min}$. A sample of $200 \mu \mathrm{L}$ of Candida albicans (different colony forming units) was added to the paper device and incubated at $37{ }^{\circ} \mathrm{C}$ for $15 \mathrm{~min}$. Later, $80 \mu \mathrm{L}$ of the colorimetric indicator DCA was added all over the sample zone and observed for pink colour formation for $30 \mathrm{~min}$.
Proteinase K treatment for confirmation of colour change

$10 \mu \mathrm{L}$ of $20 \mathrm{mg} / \mathrm{mL}$ Proteinase $\mathrm{K}$ was added to the $200 \mu \mathrm{L}$ suspension of $C$. albicans and heated at $56{ }^{\circ} \mathrm{C}$ for $30 \mathrm{~min}$ in a dry bath. This Proteinase $\mathrm{K}$ treated cell suspension was added to the circular inkjet-printed paper device having the drop casted PRO substrate solution and incubated at $37{ }^{\circ} \mathrm{C}$ for $15 \mathrm{~min}$. Later, $80 \mu \mathrm{L}$ of the colorimetric indicator DCA was added all over the sample zone and observed for colour change.

Image acquisition and analysis

Images of the device for barrier compatibility and colorimetric test were captured using Canon Eos 3000D DSLR camera at a fixed distance and ambient lighting. The images for the colorimetric test were captured from $10 \mathrm{~min}$ up to $30 \mathrm{~min}$ after the addition of the DCA indicator, and the average $G$ channel intensity value was measured using FIJI software. First, the images of the colorimetric test including the controls were split into red, green and blue channels in the FIJI software. Then the entire circular area of the 
test zone in the green channel image was selected, inverted and the mean intensity of the zone was measured.

\section{Results and discussion}

Inkjet printing of paper-based devices

Inkjet printed regions contain 'paraffin', a hydrophobic material which has penetrated and blocked the perforated pores of the paper due to heating. This has been confirmed by adding water in the patterned institute logo, where we observed no leakage or disruption (Fig. 2a). The surface tension of the hydrophobic formulation was found to be $20.18 \mathrm{mN} /$ $\mathrm{m}$, which is concordant with the literature (Yamada et al. 2015). Using our frugal inkjet printing, we have printed two hydrophobic line patterns of $3 \mathrm{~mm}$ width and $10 \mathrm{~mm}$ length. The non-printed region between the two printed hydrophobic lines serves as a hydrophilic channel. Upon introduction, water wicks up into the finer hydrophilic channels. Using a microscope, we assessed the hydrophilic channel's resolution. Interestingly, the channel's width is found to be $275 \mu \mathrm{m}$ (Fig. 2b).

\section{Characterization of paper-based devices}

Whatman $^{(\mathrm{R})}$ filter paper (Grade 1) is highly porous with an average pore size of $11 \mu \mathrm{m}$. The inkjet printer precisely deposited small droplets (Pico litres) of the hydrophobic formulation on paper. After the heating step $\left(100{ }^{\circ} \mathrm{C}\right.$ for $\left.15 \mathrm{~min}\right)$, paraffin molecules penetrate and block the paper pores, which in turn gives the paper the property to confine solvents. The Scanning Electron Microscopy image (Fig. 3a) reveals a stark difference between the patterned and plain surface. This result clearly attributes to the pore blockage on paper by the paraffin molecules. Using a Mitutoyo Digital Micrometer, we have also measured the hydrophobic barrier thickness, which was found to be $4 \pm 1 \mu \mathrm{m}$. From various reported studies (Schilling et al. 2012; Younas et al. 2019), it is evident that printing count as well as heating could contribute to penetration of the ink. We have optimized the number of printing or printing count (15 times) based on the water confining capability of the printed hydrophobic barriers. To assess the ink penetration in paper substrate, we have calculated grey scale intensity (using FIJI software by inverting the image) of plain as well as printed filter paper (front $\&$ rear side). The grey scale intensity values are found to be $117 \pm 5$, $154 \pm 4,145 \pm 3$ for Plain paper, Printed paper (Front) and Rear side respectively (Supplementary Figure 1). Interestingly, comparable or similar grey scale intensity values of printed and rear side corroborates to the complete penetration of paraffin-based ink from one side to other side of the paper.

A growing body of literature suggest the importance of measuring hydrohead values for plain porous substrates and coated hydrophobic substrates (Mates et al. 2014; Sen et al. 2018; Chatterjee et al. 2018). We have measured hydrohead values for the plain Whatman filter paper (Grade 1) and printed paper device (hydrophobic coated) by fixing $5 \mathrm{~mm}$ diameter circular area of the substrates at the end of a glass tube and measuring the height of water added till the water penetrated the substrates completely. The penetration pressure and the hydrohead values for the uncoated

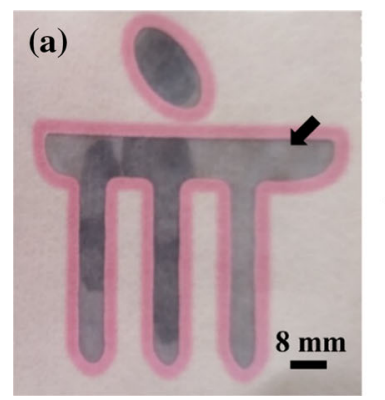

Fig. 2 a Inkjet-printed paper device (hydrophobic barrier of $3 \mathrm{~mm}$ ) with water confinement depicted by an arrow (Design: Institute logo) b Geometry of printed hydrophobic barriers and

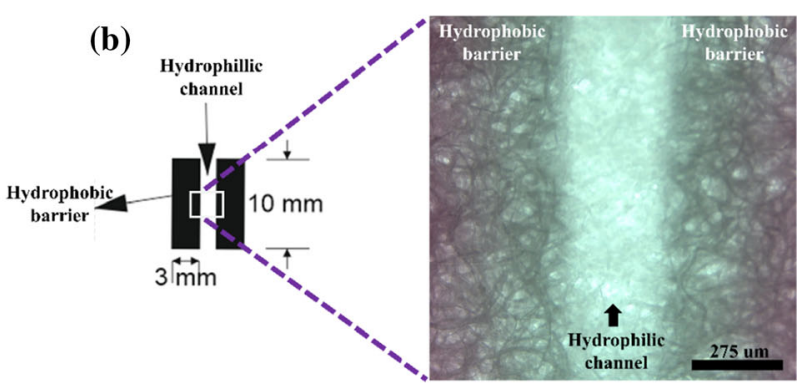

microscopic image of hydrophilic channel (wicked-up water) in transmission illumination mode (right) 
(a)

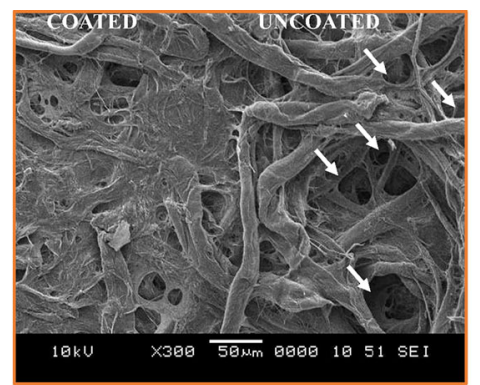

(b)

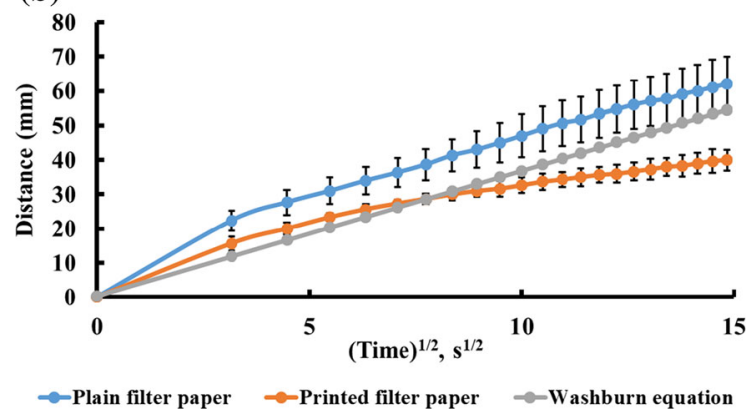

Fig. 3 a Scanning Electron Microscopy image of inkjet-printed paraffin surface and the plain surface of Whatman ${ }^{(\mathrm{R})}$ filter paper (Grade 1). b Correlating water penetration rate of the inkjetprinted channel, plain paper and Washburn equation. Each experiment was performed 3 times. Average value and \pm Standard deviation were measured

and coated filter paper are $74.91 \mathrm{~N} / \mathrm{m}^{2}$ $(7.67 \pm 1.15 \mathrm{~mm}) \quad$ and $289.87 \mathrm{~N} / \mathrm{m}^{2}$ $(29.67 \pm 2.08 \mathrm{~mm})$ respectively. Additionally, we have measured the penetration length of water (lateral direction) in the paper channels using a measuring scale and stopwatch (Supplementary Figure. 2). In an interesting study by Malekghasemi et al., the authors have compared the water penetration rate in printed filter paper-based channels and unmodified filter paper with the theoretical Washburn equation (Malekghasemi et al. 2016). In their seminal work, Hong et al., has reported that Washburn's law is not applicable to very low resolution channels formed by wax boundaries since the flow speed is dependent on the channel width, where the surface tension acts at the barrier in the inverse direction to the flow, hence lowering the flow speed (Hong and Kim 2015). We have plotted a graph comparing the water penetration rates of plain and printed filter paper with the Washburn equation (Fig. 3b). The curve for the plain paper or without barrier follows the Washburn law. However, the channels printed with paraffin-based formulation deviated from Washburn's law which is in concordance with Hong et al.

A crucial step in converting a paper into a sensing device relies on the hydrophobic barrier's compatibility to various solvents. Several researchers have examined the barrier's compatibility in paper-based devices (Dornelas et al. 2015; Wang et al. 2014; Mani et al. 2019). With this goal in mind, we have subjected the printed paraffin-based circular patterns (Fig. 4) to different solvents. We have drop-casted $30 \mu \mathrm{L}$ of solvent in circular device to assess the barrier's compatibility. Ten circular devices were taken for each solvent and further observed for any leakage of the hydrophobic barrier. Interestingly, 9 out of 10 devices exhibited ubiquitous resistance (i.e., no leakage) to all aqueous and certain polar solvents. This experiment confirms that paraffin-based barriers can be deployed for myriads of sensing applications.

\section{Colorimetric detection of Candida albicans}

To authenticate the functionality of the printed paperbased device for point-of-care diagnostics, we focused on leveraging the device for the detection of Candida albicans, a major opportunistic fungal pathogen causing invasive candidiasis among immunocompromised hosts (Mayer et al. 2013; Kullberg and Arendrup 2015; Clancy and Nguyen 2018). The traditional way of diagnosing Candida albicans includes culturebased methods and nucleic-acid testing, which are laborious, expensive and demand expert intervention. To circumvent these challenges, we have utilized L-proline $\beta$-naphthylamide (PRO) substrate targeting the enzyme L-proline aminopeptidase, secreted by Candida albicans (Perry et al. 1990) as a means of detection as its results can be interpreted without a skilled personnel (Supplementary Figure 3). Firstly, L-proline $\beta$-naphthylamide (PRO) substrate was imbibed on the printed paper device. Upon addition of pathogenic Candida albicans, L-proline aminopeptidase hydrolyses the L-proline $\beta$-naphthylamide (PRO) substrate, resulting in a visible pink colour within $10 \mathrm{~min}$, after adding the indicator (Fig. 5a), which is a significant and easy way to interpret the result. When compared to existing microbial identification methods like BacT/ALERT, Culture \& VITEK system which cost between 10 and $15 \$$ per sample. This approach greatly reduces cost $(<0.20 \$)$, can be used as a presumptive identification test for Candida 


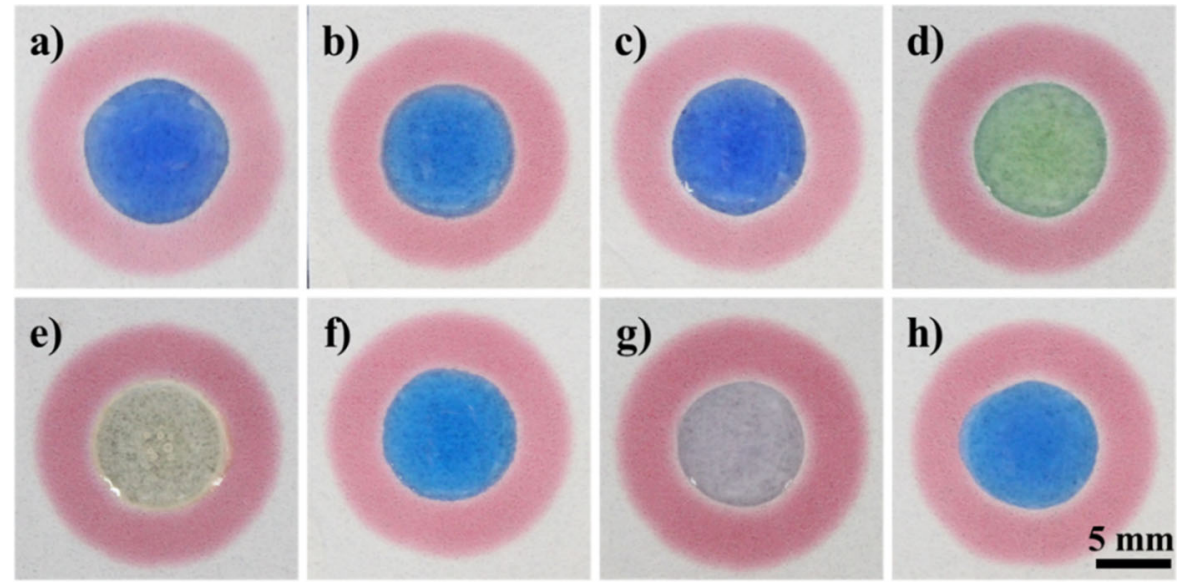

Fig. 4 Solvent compatibility of paraffin-based hydrophobic barriers a Water b $40 \%$ Ethanol c 1 X PBS d 1 N HCl e Tween-80 f $1 \%$ Triton X-100 g $1 \mathrm{~N} \mathrm{NaOH} \mathbf{h}$ Acetonitrile. Volume added $30 \mu \mathrm{l}(\mathbf{a}, \mathbf{b}, \mathbf{c}, \mathbf{d}, \mathbf{f}, \mathbf{h}$ are coloured with dye)

albicans. This method can also be extended further to other pathogen detection assays as well.

To confirm that this distinct colour change (pink) is due to the secretory enzyme from Candida albicans and not due to artefacts, we have carried out two confirmatory studies. In the first study, we treated the C. albicans cell suspension as well as the supernatant with Proteinase $\mathrm{K}$ solution by heating it at $56{ }^{\circ} \mathrm{C}$ for $30 \mathrm{~min}$. Then the proteinase $\mathrm{K}$ treated inoculum suspension and the supernatant were added to the paper device (with PRO substrate) and incubated at $37{ }^{\circ} \mathrm{C}$ for $15 \mathrm{~min}$. Upon addition of the cinnamaldehyde indicator, no colour change to pink was observed in the paper device (Fig. 5b). In the second study, we have performed the same qualitative colorimetric assay for other fungi like $S$. cerevisiae and Candida tropicalis. Similarly, we didn't observe amenable colour change (Fig. 5c). Moreover, our results have been concordant with existing literature which confirms that L-proline aminopeptidase is not secreted by these organisms (Rawlings and Salvesen 2013). Both these tests prove that the colour change is due to the presence of a secretory enzyme (L-proline aminopeptidase) from the organism, which when disrupted, doesn't give the colour change to pink.

Additionally, we have measured the $\mathrm{G}$ channel intensity values of the control and test sample images. Figure 6 depicts the sudden increase in the $G$ channel intensity value. This change is attributed to the hydrolysis of L-proline $\beta$-naphthylamide (PRO) by the enzyme L-proline aminopeptidase secreted by Candida albicans resulting in a visible colour change within $10 \mathrm{~min}$, which can pave the way for frugal diagnostics. To analyse the limit of detection (LOD) for the developed paper-based colorimetric test, we used different Candia albicans suspensions at varying concentrations $\left(0.86-8.35 \times 10^{6} \mathrm{cfu} / \mathrm{mL}\right)$. Interestingly, cell samples less than $0.86 \times 10^{6} \mathrm{cfu} / \mathrm{mL}$ induced no amenable colour change to pink, and the $\mathrm{G}$ channel intensity of the samples was similar to the control values with little higher intensity value (may be due to the addition of colorimetric DCA indicator). Figure 7 shows an increasing trend in the $G$ channel intensity for an increase in the concentration of the cells. Strikingly, samples of $8.35 \times 10^{6} \mathrm{cfu} / \mathrm{mL}$ and above showed significant visible pink colour with higher $\mathrm{G}$ intensity values.

Finally, we have assessed shelf-life of the device by drop-casting L-proline $\beta$-naphthylamide (PRO) in the paper-based device. A similar pink colour was observed for the device stored at $4{ }^{\circ} \mathrm{C}$ for 1 month (Data not shown). Moreover, no leakage from the paper-device was observed during this experiment. An outline of cost analysis, based on (i) fabrication of paper-based devices (using ColorQube), (ii) conventional diagnostic method for fungi with our frugal method is provided in the supplementary material. It is clear from the results that the paraffin-based fabrication method can potentially replace cumbersome bulk experiments. Our method boasted fabrication of devices with adequate shelf life for long-term usage, which would be especially useful in the case of resource-constrained settings for point-of-care detection. 
Control (Without C. albicans)

With C. albicans
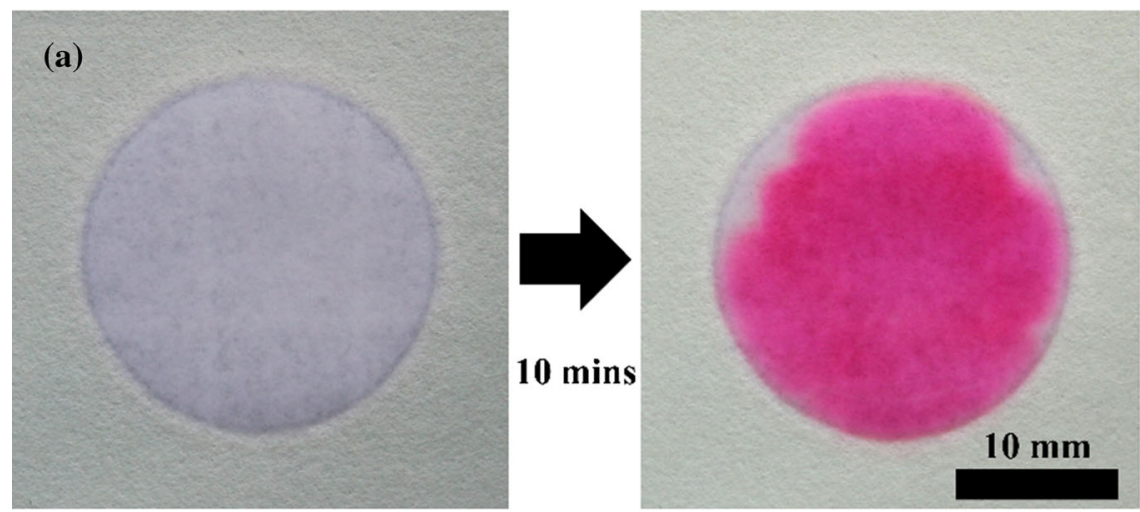

C. albicans + Proteinase $\mathrm{K}$

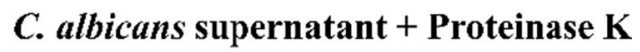

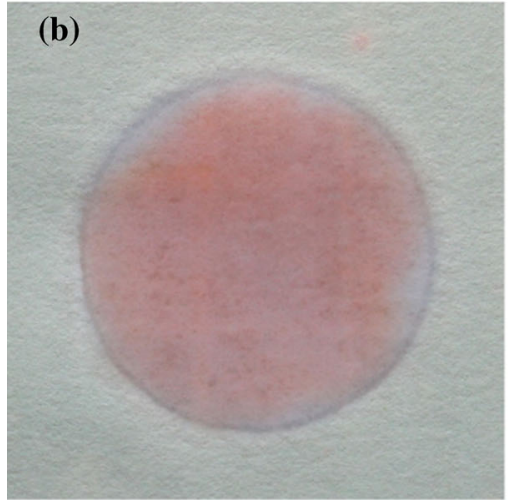

10 mins

S. cerevisiae

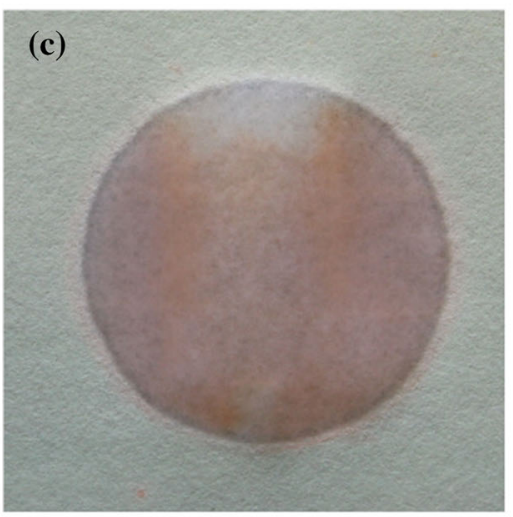

10 mins

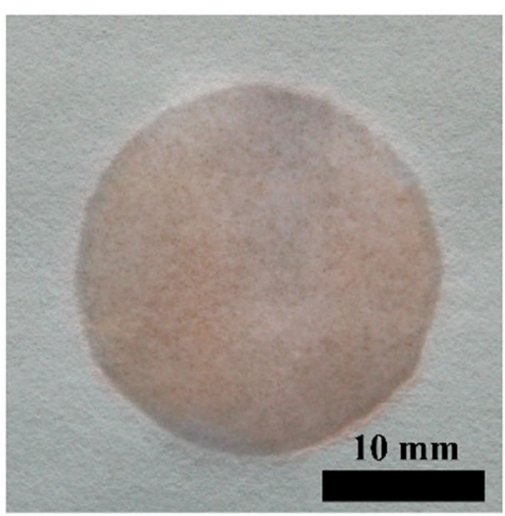

10 mins

C. tropicalis

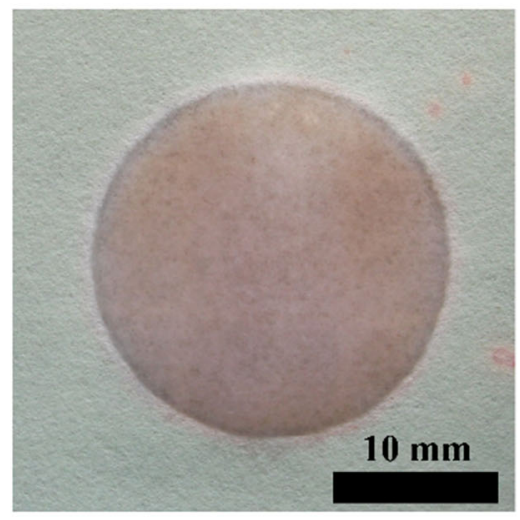

$10 \mathrm{mins}$

Fig. 5 Paper-based colorimetric assay a Without Candida albicans-No colour and with Candida albicans-Pink colour b Candida albicans cell suspension and supernatant treated with Proteinase K. c Saccharomyces cerevisiae and Candida tropicalis (No colour) 


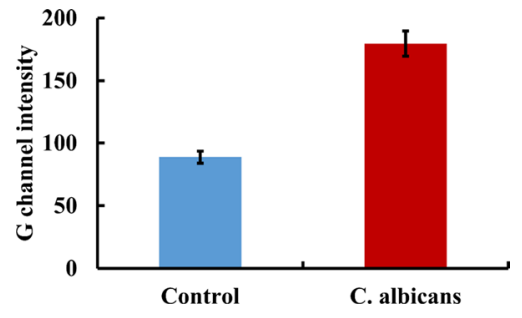

Fig. $6 \mathrm{G}$ channel intensity of control and Candida albicans. Each data point contains 3 samples. Average grey value and \pm Standard deviation were measured

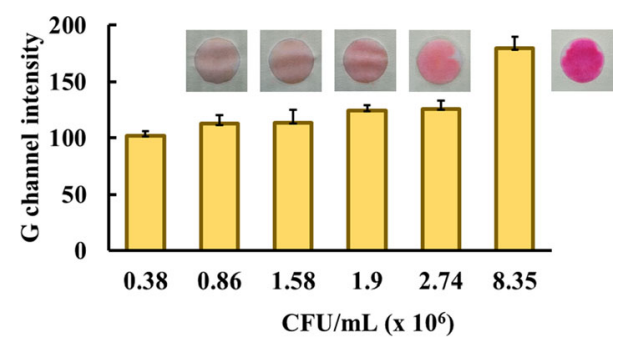

Fig. 7 G channel intensity of various Candida albicans cell suspension. Each data point contains 3 samples. Average grey value and \pm Standard deviation were measured

\section{Conclusion}

To recapitulate, in this work, we have described the development of a cost-effective $(<0.20 \$)$ paperbased device leveraged for point-of-care detection of pathological fungi. The paper-based device was fabricated by inkjet printing an in-house formulated paraffin ink. The printed designs exhibited hydrophobic property due to the penetration of the paraffin into the paper pores which rendered them capable of confining major aqueous solutions and other solvents. The functionality of the fabricated paper device was validated through a colorimetric test developed for Candida albicans (a common fungal pathogen). Our study provides the framework for converting a simple desktop printer into a high throughput paper-device fabrication unit. In our opinion, the results represent an excellent initial step towards the development of frugal and robust fabrication methods for point-of-care sensing or diagnostics with the scope of extending it to smart-phone based studies.

Acknowledgments We acknowledge the financial support from Manipal McGill Centre for Infectious Diseases [Seed Grant Award Number: MAC ID/SGA/2017/21]. NKM \& AP acknowledge the financial support from Vision Group on Science and Technology, Government of Karnataka under
SMYSR and RGS/F Scheme [Sanction Letter no.: KSTePS/ VGST/SMYSR-2016-17/GRD-595/2017-18, KSTePS/ VGSTRGS/F/GRD No.711/2017-18]. AP acknowledges Indian Council of Medical Research (ICMR) for providing Senior Research Fellowship [File no: 5/3/8/91/ITR-F/2020]. NKM acknowledges Prof. Guillermo Orellana, Complutense University of Madrid for his valuable suggestions. We extend our special thanks to Prof. Suman Chakraborty, Department of Mechanical Engineering, Indian Institute of Technology, Kharagpur for providing SEM facility and Department of Biotechnology, Manipal Institute of Technology. GN acknowledges Science and Engineering Research Board (SERB), Department of Science and Technology, Govt of India for National Post-Doctoral Fellowship [Sanction No: PDF/2018/001486]. We thank the editor and reviewers for their feedback and suggestions. NKM acknowledges Dr. Praveen Kumar, Dr. Vijendra Prabhu and Dr. Ujjwal Verma for the fruitful discussions.

Funding Open access funding provided by Manipal Academy of Higher Education, Manipal.

\section{Compliance with ethical standards}

Conflict of interest There are no conflicts to declare.

Open Access This article is licensed under a Creative Commons Attribution 4.0 International License, which permits use, sharing, adaptation, distribution and reproduction in any medium or format, as long as you give appropriate credit to the original author(s) and the source, provide a link to the Creative Commons licence, and indicate if changes were made. The images or other third party material in this article are included in the article's Creative Commons licence, unless indicated otherwise in a credit line to the material. If material is not included in the article's Creative Commons licence and your intended use is not permitted by statutory regulation or exceeds the permitted use, you will need to obtain permission directly from the copyright holder. To view a copy of this licence, visit http://creativecommons.org/licenses/by/4.0/.

\section{References}

Abe K, Suzuki K, Citterio D (2008) Inkjet-printed microfluidic multianalyte chemical sensing paper. Anal Chem 80:6928-6934. https://doi.org/10.1021/ac800604v

Ahmed S, Bui M-PN, Abbas A (2016) Paper-based chemical and biological sensors: engineering aspects. Biosens Bioelectron 77:249-263. https://doi.org/10.1016/j.bios.2015. 09.038

Carrilho E, Martinez AW, Whitesides GM (2009) Understanding wax printing: a simple micropatterning process for paper-based microfluidics. Anal Chem 81:7091-7095. https://doi.org/10.1021/ac901071p

Chatterjee S, Sinha Mahapatra P, Ibrahim A et al (2018) Precise liquid transport on and through thin porous materials. Langmuir 34:2865-2875. https://doi.org/10.1021/acs. langmuir.7b04093 
Chow J, Lee SM, Shen Y, et al (2010) Host-bacterial symbiosis in health and disease. In: Advances in immunology. pp 243-274

Clancy CJ, Nguyen MH (2018) Diagnosing invasive candidiasis. J Clin Microbiol 56:e01909-e1917. https://doi.org/10. 1128/JCM.01909-17

Dornelas KL, Dossi N, Piccin E (2015) A simple method for patterning poly(dimethylsiloxane) barriers in paper using contact-printing with low-cost rubber stamps. Anal Chim Acta 858:82-90. https://doi.org/10.1016/j.aca.2014.11.025

Dungchai W, Chailapakul O, Henry CS (2011) A low-cost, simple, and rapid fabrication method for paper-based microfluidics using wax screen-printing. Analyst 136:77-82. https://doi.org/10.1039/C0AN00406E

e Silva RF, Longo Cesar Paixão TR, Der Torossian TM, de Araujo WR (2020) Simple and inexpensive electrochemical paper-based analytical device for sensitive detection of Pseudomonas aeruginosa. Sens Actuators B Chem. https:// doi.org/10.1016/j.snb.2020.127669

Elsharkawy M, Schutzius TM, Megaridis CM (2014) Inkjet patterned superhydrophobic paper for open-air surface microfluidic devices. Lab Chip 14:1168-1175. https://doi. org/10.1039/c31c51248g

Goluch ED (2017) Microbial identification using electrochemical detection of metabolites. Trends Biotechnol 35:1125-1128. https://doi.org/10.1016/j.tibtech.2017.08. 001

Haller PD, Flowers CA, Gupta M (2011) Three-dimensional patterning of porous materials using vapor phase polymerization. Soft Matter 7:2428. https://doi.org/10.1039/ c0sm01214a

He Q, Ma C, Hu X, Chen H (2013) Method for fabrication of paper-based microfluidic devices by alkylsilane selfassembling and $\mathrm{UV} / \mathrm{O}_{3}$-patterning. Anal Chem 85:1327-1331. https://doi.org/10.1021/ac303138x

Hong S, Kim W (2015) Dynamics of water imbibition through paper channels with wax boundaries. Microfluid Nanofluid 19:845-853. https://doi.org/10.1007/s10404-015-1611-3

Kou S, Cheng D, Sun F, Hsing IM (2016) Microfluidics and microbial engineering. Lab Chip 16:432-446. https://doi. org/10.1039/c5lc01039j

Kullberg BJ, Arendrup MC (2015) Invasive candidiasis. N Engl J Med 373:1445-1456. https://doi.org/10.1056/ NEJMra1315399

Kwong P, Gupta M (2012) Vapor phase deposition of functional polymers onto paper-based microfluidic devices for advanced unit operations. Anal Chem 84:10129-10135. https://doi.org/10.1021/ac302861v

Law JWF, Mutalib NSA, Chan KG, Lee LH (2014) Rapid methods for the detection of foodborne bacterial pathogens: principles, applications, advantages and limitations. Front Microbiol 5:1-19. https://doi.org/10.3389/fmicb. 2014.00770

Lazcka O, Del CFJ, Muñoz FX (2007) Pathogen detection: a perspective of traditional methods and biosensors. Biosens Bioelectron 22:1205-1217. https://doi.org/10.1016/j.bios. 2006.06.036

Lee J, Samson AAS, Song JM (2018) Peptide substrate-based inkjet printing high-throughput MMP-9 anticancer assay using fluorescence resonance energy transfer (FRET). Sens
Actuators B Chem 256:1093-1099. https://doi.org/10. 1016/j.snb.2017.10.051

Li X, Tian J, Nguyen T, Shen W (2008) Paper-based microfluidic devices by plasma treatment. Anal Chem 80:9131-9134. https://doi.org/10.1021/ac801729t

Li X, Tian J, Garnier G, Shen W (2010) Fabrication of paperbased microfluidic sensors by printing. Colloids Surf B Biointerfaces 76:564-570. https://doi.org/10.1016/j. colsurfb.2009.12.023

Li X, Ballerini DR, Shen W (2012) A perspective on paperbased microfluidics: current status and future trends. Biomicrofluidics 6:12-14. https://doi.org/10.1063/1. 3687398

Lin D, Li B, Qi J et al (2020) Low cost fabrication of microfluidic paper-based analytical devices with waterbased polyurethane acrylate and their application for bacterial detection. Sens Actuators B Chem. https://doi.org/10. 1016/j.snb.2019.127213

Liu KF, Li PP, Zhang YP et al (2019) Laboratory filter paper from superhydrophobic to quasi-superamphiphobicity: facile fabrication, simplified patterning and smart application. Cellulose 26:3859-3872. https://doi.org/10.1007/ s10570-019-02338-8

Lu Y, Shi W, Jiang L et al (2009) Rapid prototyping of paperbased microfluidics with wax for low-cost, portable bioassay. Electrophoresis 30:1497-1500. https://doi.org/10. 1002/elps.200800563

Malekghasemi S, Kahveci E, Duman M (2016) Rapid and alternative fabrication method for microfluidic paper based analytical devices. Talanta 159:401-411. https://doi.org/ 10.1016/j.talanta.2016.06.040

Mani NK, Rudiuk S, Baigl D (2013) Spatially controlled DNA unzipping by microfluidic interface positioning on a molecule perpendicular to a multicomponent flow. Chem Commun 49:6858. https://doi.org/10.1039/c3cc44016h

Mani NK, Prabhu A, Biswas SK, Chakraborty S (2019) Fabricating paper based devices using correction pens. Sci Rep 9:1752. https://doi.org/10.1038/s41598-018-38308-6

Mani NK, Das SS, Dawn S, Chakraborty S (2020) Electro-kinetically driven route for highly sensitive blood pathology on a paper-based device. Electrophoresis. https://doi.org/ 10.1002/elps.201900356

Mates JE, Schutzius TM, Qin J et al (2014) The fluid diode: tunable unidirectional flow through porous substrates. ACS Appl Mater Interfaces 6:12837-12843. https://doi.org/10. 1021/am5028204

Matsuda Y, Kameya T, Suzuki Y et al (2017) Fine printing of pressure- and temperature-sensitive paints using commercial inkjet printer. Sens Actuators B Chem 250:563-568. https://doi.org/10.1016/J.SNB.2017.04.188

Mayer FL, Wilson D, Hube B (2013) Candida albicans pathogenicity mechanisms. Virulence 4:119-128. https:// doi.org/10.4161/viru.22913

Nasseri B, Soleimani N, Rabiee N et al (2018) Point-of-care microfluidic devices for pathogen detection. Biosens Bioelectron 117:112-128. https://doi.org/10.1016/j.bios.2018. 05.050

Nilghaz A, Liu X, Ma L et al (2019) Development of fabricbased microfluidic devices by wax printing. Cellulose 26:3589-3599. https://doi.org/10.1007/s10570-019$02317-\mathrm{z}$ 
Olkkonen J, Lehtinen K, Erho T (2010) Flexographically printed fluidic structures in paper. Anal Chem 82:10246-10250. https://doi.org/10.1021/ac1027066

OuYang L, Wang C, Du F et al (2014) Electrochromatographic separations of multi-component metal complexes on a microfluidic paper-based device with a simplified photolithography. RSC Adv 4:1093-1101. https://doi.org/10. 1039/C3RA43625J

Perry JL, Miller GR, Carr DL (1990) Rapid, colorimetric identification of Candida albicans. J Clin Microbiol 28:614-615

Potter J, Brisk P, Grover WH (2019) Using printer ink color to control the behavior of paper microfluidics. Lab Chip 19:2000-2008. https://doi.org/10.1039/c9lc00083f

Prestinaci F, Pezzotti P, Pantosti A (2015) Antimicrobial resistance: a global multifaceted phenomenon. Pathogens Global Health 109:309-318. https://doi.org/10.1179/ 2047773215Y.0000000030

Priyanka B, Patil RK, Dwarakanath S (2016) A review on detection methods used for foodborne pathogens. Indian $\mathrm{J}$ Med Res 144:327-338. https://doi.org/10.4103/09715916.198677

Punpattanakul K, Kraduangdej S, Jiranusornkul N et al (2018) A novel patterning method for three-dimensional paperbased devices by using inkjet-printed water mask. Cellulose 25:2659-2665. https://doi.org/10.1007/s10570-018$1712-8$

Rajapaksha P, Elbourne A, Gangadoo S et al (2019) A review of methods for the detection of pathogenic microorganisms. Analyst. https://doi.org/10.1039/C8AN01488D

Rawlings ND, Salvesen G (2013) Handbook of proteolytic enzymes. Elsevier Ltd, Berkeley

Rosati G, Ravarotto M, Scaramuzza M et al (2019) Silver nanoparticles inkjet-printed flexible biosensor for rapid label-free antibiotic detection in milk. Sens Actuators B Chem 280:280-289. https://doi.org/10.1016/j.snb.2018.09. 084

Sameenoi Y, Nongkai PN, Nouanthavong S et al (2014) Onestep polymer screen-printing for microfluidic paper-based analytical device $(\mu \mathrm{PAD})$ fabrication. Analyst 139:6580-6588. https://doi.org/10.1039/C4AN01624F

Savary S, Willocquet L, Pethybridge SJ et al (2019) The global burden of pathogens and pests on major food crops. Nat Ecol Evolut 3:430-439. https://doi.org/10.1038/s41559018-0793-y

Schilling KM, Lepore AL, Kurian JA, Martinez AW (2012) Fully enclosed microfluidic paper-based analytical devices. Anal Chem 84:1579-1585. https://doi.org/10.1021/ ac202837s

Sen U, Chatterjee S, Sinha Mahapatra P et al (2018) Surfacewettability patterning for distributing high-momentum water jets on porous polymeric substrates. ACS Appl Mater Interfaces 10:5038-5049. https://doi.org/10.1021/acsami. $7 \mathrm{~b} 13744$

Songjaroen T, Dungchai W, Chailapakul O, Laiwattanapaisal W (2011) Novel, simple and low-cost alternative method for fabrication of paper-based microfluidics by wax dipping. Talanta 85:2587-2593. https://doi.org/10.1016/j.talanta. 2011.08.024
Songok J, Tuominen M, Teisala H et al (2014) Paper-based micro fluidics: fabrication technique and dynamics of capillary-driven surface flow. ACS Appl Mater Interfaces 6:20060-20066. https://doi.org/10.1021/am5055806

Su W, Cook BS, Fang Y, Tentzeris MM (2016) Fully inkjetprinted microfluidics: a solution to low-cost rapid threedimensional microfluidics fabrication with numerous electrical and sensing applications. Sci Rep 6:35111. https://doi.org/10.1038/srep35111

Tang RH, Li M, Liu LN et al (2020) Chitosan-modified nitrocellulose membrane for paper-based point-of-care testing. Cellulose. https://doi.org/10.1007/s10570-020-03031-x

Váradi L, Luo JL, Hibbs DE et al (2017) Methods for the detection and identification of pathogenic bacteria: past, present, and future. Chem Soc Rev 46:4818-4832. https:// doi.org/10.1039/c6cs00693k

Wang Y, Salazar JK (2016) Culture-independent rapid detection methods for bacterial pathogens and toxins in food matrices. Compr Rev Food Sci Food Saf 15:183-205. https:// doi.org/10.1111/1541-4337.12175

Wang J, Monton MRN, Zhang X et al (2014) Hydrophobic solgel channel patterning strategies for paper-based microfluidics. Lab Chip 14:691-695. https://doi.org/10. 1039/c3lc51313k

Whitesides GM (2006) The origins and the future of microfluidics. Nature 442:368-373. https://doi.org/10.1038/ nature 05058

Wormser GP, Ryan KJ (2003) Medically important fungi: a guide to identification, 4th Edition Davise H. Larone, Washington, D.C.: American Society for Microbiology Press, 2002. Clin Infect Dis 37:1281-1281. https://doi.org/ $10.1086 / 378813$

Xiao G, He J, Chen X et al (2019) A wearable, cotton thread/paper-based microfluidic device coupled with smartphone for sweat glucose sensing. Cellulose 26:4553-4562. https://doi.org/10.1007/s10570-01902396-y

Yamada K, Henares TG, Suzuki K, Citterio D (2015) Paperbased inkjet-printed microfluidic analytical devices. Angew Chem Int Ed 54:5294-5310. https://doi.org/10. 1002/anie. 201411508

Yang Y, Noviana E, Nguyen MP et al (2017) Paper-based microfluidic devices: emerging themes and applications. Anal Chem 89:71-91. https://doi.org/10.1021/acs. analchem.6b04581

Yeo LY, Chang H-C, Chan PPY, Friend JR (2011) Microfluidic devices for bioapplications. Small 7:12-48. https://doi.org/ 10.1002/smll.201000946

Younas M, Maryam A, Khan M et al (2019) Parametric analysis of wax printing technique for fabricating microfluidic paper-based analytic devices ( $\mu \mathrm{PAD})$ for milk adulteration analysis. Microfluid Nanofluid 23:1-10. https://doi.org/10. 1007/s10404-019-2208-z

Publisher's Note Springer Nature remains neutral with regard to jurisdictional claims in published maps and institutional affiliations. 